\title{
Couplings: Agon and Composition in Paul Muldoon's Ekphrastic Poetry
}

\author{
By Rui Carvalho Homem, University of Oporto, Portugal
}

Copyright (c) 2005 by Rui Carvalho Homem. This text may be archived and redistributed in electronic form, provided that the author and journal are properly cited and no fee is charged for access. Archiving, redistribution, or republication of this text on other terms, in any medium, requires the notification of the journal and consent of the author.

\begin{abstract}
In the course of more than thirty years of prolific writing, Paul Muldoon has earned a reputation for surprising his readers again and again. To a significant extent, this continued ability to "make it new" is closely linked to Muldoon's characteristically relational writing. Often described (in tones of eulogy or of deprecation) as the epitome of a postmodernist practice, his work has tested the limits of intertextuality - and his penchant for quotation, pastiche and parody has rather often sought referents in other media, notably in the visual arts. Taking a specific instance of ekphrasis in Muldoon's poetry for its point of departure and its focus, this article proceeds to address broader themes in his work, as well as to consider his practice against the framework defined by a major alternative for reading the relationship between word and image: as rivalry and struggle, or as peaceful and mutual enablement.
\end{abstract}

Key Words: Muldoon, postmodernism, intertextuality, intermediality, ekphrasis

In the course of more than thirty years of prolific writing, Paul Muldoon has earned a reputation for surprising his readers again and again. To a significant extent, this continued ability to "make it new" is closely linked to Muldoon's characteristically relational writing. Often described (in tones of eulogy or of deprecation) as the epitome of a postmodernist practice, his work has tested the limits of intertextuality -and his penchant for quotation, pastiche and parody has rather often sought referents in other media, notably in the visual arts. Such formal strategies duly find their representational match in objects and beings whose identity (social, familial, biological —all of these with a potential political undertow) is characteristically indecisive, half-way or hybrid; and, parallel to his poetry, his (comparatively scant) critical writings have tended to stress an interest in "promicuous provenance", and in texts that foreground "a range of strategies ... for dealing with the ideas of liminality and narthecality" (Muldoon 2000: 5). In connection with these features, that he believes to be central to an Irish verbal and representational culture, Muldoon has coined two memorable words, "conglomewriting" and "imarrhage", by which he means the tendency "towards the amalgam, the tendency for one event or character to blur and bleed into another" (Muldoon 2000: 56, $74,77)$.

These are some of the features that have contributed to Muldoon's fame in the present critical environment - but also to some misgivings around his willingness to gratify current expectations, and in particular to write with an academic audience in mind whose critical and political values he so completely seems to meet. Not surprisingly, a fair share of the critical appreciation Muldoon has recently obtained wonders about the degree of irony to be read beneath this (real or apparent) complacency, this willingness to provide a favourite drilling ground for reading strategies nourished by the allure of indeterminacy ( $\mathrm{cf}$ Kendall and McDonald 2004: 1-5; Lyon 2004: passim). In much of what follows I will be 
concerned with the intersection between this equivocal position with regard to current critical mores and the intermedial nexus as prompted by Muldoon's practice of ekphrasis. My point of departure will be a poem published in 2002, and known to most readers as "Anthony Green: The Second Marriage", included in Muldoon's collection Moy Sand and Gravel. By this formula ("known to most readers as...") I mean to signal the fact that the poem was originally commissioned for a publication on poetry and art promoted by the National Museums and Galleries of Northern Ireland, which asked a number of poets to respond to art work in the Northern Irish collections; and that in the ensuing volume A Conversation Piece, also issued in 2002Muldoon's contribution appeared exactly under the same title as the painting: in full, $M r$ and Mrs Stanley Joscelyne: The Second Marriage.

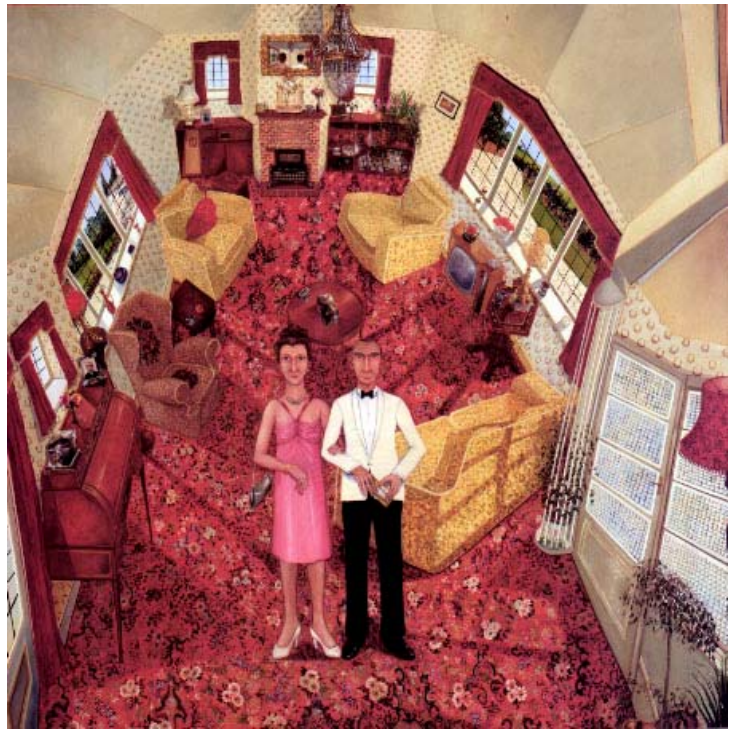

Mr and Mrs Stanley Joscelyne: The Second Marriage (1972) by Anthony Green. Oil on board. Courtesy of Anthony Green and Ulster Museum.

The change in the title will have been made for obvious reasons: in A Conversation Piece the poem appears next to a reproduction of the painting it purports to represent, and the painting's authorship is duly identified whereas in Moy Sand and Gravel no such reproduction is included, and Muldoon will have felt the need to supply the painter's name. However, he chooses not to retain that part of the title which identifies the painting's empirical and (indeed) familial reference; (the reader will not have to go farther than an endnote in A Conversation Piece to learn that "most of Green's work is to do with members of his own family" and that the living room which provides this painting's setting "is that of Green's parents' home in north London" Rice and Reid 2002: 147).

This apparently minor change in the title is not, however, devoid of further implications which may prove relevant to my topic. Naming the painter in the poem's title is a gesture of inter-authorial deference which contributes to Muldoon's ambivalence with regard to authorship and a sense of the original. As pointed out above, this is a poet whose practice of pastiche, parody, quotation (often truncated and unacknowledged) and generally of all forms of intertextuality has afforded him the reputation of epitomising postmodernist writing understood as ineluctably rewriting; but this same poet, in his less common role as a critic, may also declare, as in his essay titled "Getting Round: Notes Towards an Ars Poetica", "Let the theorists get over themselves. Let Barthes claim that there is no 'father-author'. Let Derrida proclaim against 'phallologocentrism'. Let them try to get round the ungetroundable fact that the poet is the first person to read or, more importantly, to be read by, the poem" (Muldoon 1998: 120).

I will not dwell, at this stage, on the extent to which that parenthetical segment in the latter sentence drastically undermines the authoritativeness and the rhetoric of dismissal of the preceding sentences (after all, as John Lyon remarks, "Muldoon ... [pursues] an inclusiveness of declarations which is not shy of what may be described, kindly as paradox, cruelly as contradiction" - Lyon 2004: 119). I will rather return to Muldoon's "Anthony Green: The Second Marriage" to point out that, since the title of the poem, when set against the title of the painting, seems to "replace" the figures named and represented by Green with Green's own name, it might appear to convert the author of the pictorial representation himself into a referent for the verbal representation of the painting -an expectation which, even if not substantiated by the poem in any literal way, is somehow gratified by the refiguration of its object that (as argued below) Muldoon will indeed effect. However, Muldoon's rephrasing of the title makes it identical to the label on a museum wall, indicating author and title of the work on display, and this certainly reinforces the 
substitutive value which the conventional ekphrastic poem may claim vis-à-vis its pictorial object. Paradoxically, thus, giving the poem a somewhat different title from that of the painting it purports to describe seems in this case to reinforce the suggestion that the verbal appropriation of the visual is ruled by literality.

The reading that follows will hardly confirm the latter expectation, but it should be noticed that, on the one hand, the apparent promise of a "simple", "transparent" matching of verbal and pictorial representations summons one of the most persistent topoi in the discursive history of the relation between word and image - the benign version of this relation as signified in the "sister arts", $u t$ pictura strand of that discursive history, as against the various forms taken by the oppositional, agonistic (or rather, paragonal) view of the rapport between verbal and visual. On the other hand, this prospect of a "peaceful" refiguration in another medium seems to find a thematic correlative in the wedding scene, itself a topos of promised harmony and stability.

True it is that the title (of poem and painting) promises a "second marriage" somehow qualifying expectations of the original, the singular (even of the virginal): more of this later, since before proceeding a reminder is due that family relations, and marriage in particular, recur as a theme in Muldoon, but they are usually shadowed by a sense of mismatch or dysfunction, a scene of disturbed and disturbing attachments, with a special autobiographical bearing on parental figures. The setting is often one of undeclared struggle, the mother figure tending to appear as overbearing, even in (and from) the grave: "though she preceded him / by a good ten years, my mother's skeleton / has managed to worm / its way back on top of the old man's, / and she once again has him under her thumb." ("Oscar", Muldoon 2001: 329); ultimately, her repressive, castrating power over her husband finds its effect and its continuity in their son's inability to tell one from the other: "He'd mistaken his mother's name, 'Regan', for 'Anger': / as he knelt by the grave of his mother and father / he could barely tell one from the other" ("Milkweed and Monarch", Muldoon 2001: 330). In a way which is also relevant to the relational designs with which I am concerned, medially and thematically,
Muldoon's representations of the family as freakish and dysfunctional intersect with his also recurrent theme (and practice) of hybridity, a good example emerging with that narrative of a strangely mixed lineage offered, half in direct speech half in inner discourse, at the opening of his poem "Immram":

"Your old man was an ass-hole.

That makes an ass-hole out of you."

My grand-father hailed from New York State.

My grand-mother was part Cree.

This must be some new strain in my pedigree.

(Muldoon 2001: 94)

As readers of Muldoon's work are bound to remember, the theme of mongrel identity had its most memorable anchorage in his 1977 collection Mules, and within it an openly autobiographical realisation of that theme with regard to family identity could be found in the aptly titled "The Mixed Marriage", a poem about a "servant-boy" father and a "schoolmistress" mother which contained a motto for Muldoon's poetically recurrent sense of an inbetween origin and identity: "I flitted between a hole in the hedge / And a room in the Latin Quarter" (Muldoon 2001: 60). But both themes had another meeting point in that volume, and one which was matched by an intermedial design: the ekphrastic poem "The Bearded Woman, by Ribera".

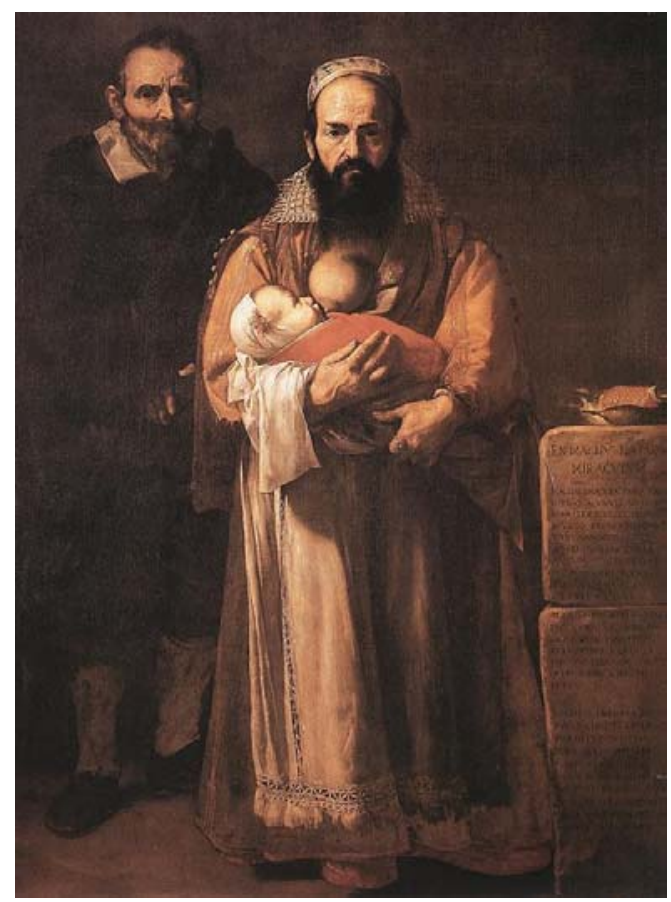

The Bearded Woman (1631) by José de Ribera Hospital de Tavera, Toledo 
Having dealt elsewhere in some detail with this topic and this poem, and in particular with its refiguration of the seventeenth-century painting of the same title (cf Homem 2004), I will merely point out, first, that a key to the way in which Muldoon's ekphrastic rendering positions the painting in relation to pictorial traditions, and a key as well to the ruling nexus of Muldoon's refiguration of Ribera's referents, can be found, half-way down the poem, in the lines: "Might this be the Holy Family / Gone wrong?" (Muldoon 2001: 57); secondly, that Muldoon offers the reader who may be curious enough to check the poem against its pictorial referent the surprise of finding that the ostensibly "literal" description of the painting is deceitful; thirdly, in more general terms, with the privilege of retrospection, and for the sake of a vantage point on "Anthony Green: The Second Marriage", that "The Bearded Woman, by Ribera" confirms the recurrence of Muldoon's interest in offering verbal representations of visual representations of unconventional (or somehow challenging) couplings.

This realisation feeds into one of the senses in which Muldoon's poem on (or after) Anthony Green's painting is "The Second Marriage" — not in a literally ordinal way, but rather in the sense that its thematic scope finds precedents in Muldoon's work and in the verbal and visual intertexts that it constitutes. This does not in any way occlude the most immediate sense of that secondariness as it comes across to the viewer of Green's painting, signified in the middle-aged features of the couple portrayed (the wrinkles on their foreheads are especially graphic). Together with the title, such features constitute a visually explicit countering of the expectation that a wedding scene (suggested by the groom's dinner jacket and the bride's rather formal pink dress) would have young protagonists and would stand for a sense of origin and of the once-only; in Muldoon's poem this perception is validated by the remark that the two figures are hardly "reminiscent ... of a blushing bride and a nervous groom" (Muldoon 2002: 32). As suggested above, this sense of recurrence or repetition is particularly congenial to Muldoon's intertextual practice, but also Green seems to be only too conscious of other ways in which his painting is secondary, ways in which it has precursors that it quotes, ironically or otherwise. One such precursor, in fact acknowledged in the editorial notes to $A$ Conversation Piece, and whose productiveness to any reading is magnified by the vastness of its cultural and representational consequence, is one of the fundamental pictorial topoi for the representation of the married couple in European art -Van Eyck's Portrait of Giovanni Arnolfini and his Wife ${ }^{1}$.

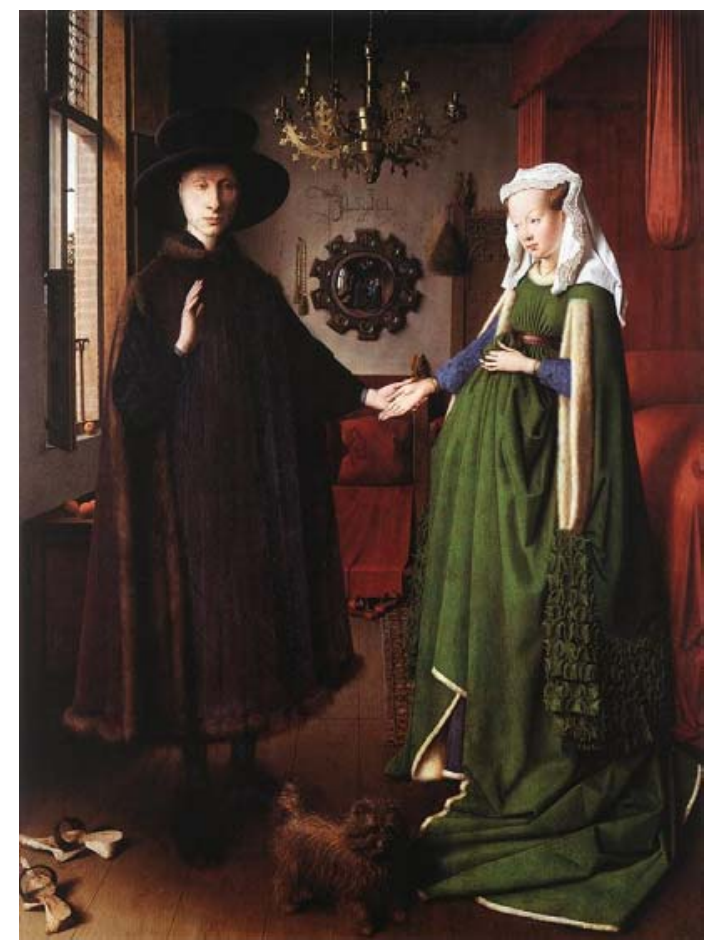

Portrait of Giovanni Arnolfini and his Wife (1434) By Van Eyck, National Gallery, London

It is arguable that the couple's pose might be enough for the visual intertext to be recognisable, but Green makes it visually explicit through two furnishings that easily gain the value of synecdoches for the Arnolfini portrait: the chandelier, and the mirror on the wall at the back of the scene. The latter element proves especially enlightening with regard to the kind of representational rapport that Green establishes with Van Eyck's painting - and to the awareness Muldoon may have of such rapport. Van Eyck's convex mirror reflects, not only the backs of the Arnolfini couple, but also human shapes that face them, figures that stand where the beholder (or the portraying artist?) would stand. It is certainly relevant in this respect that right above the mirror (at a conspicuously central point) Van Eyck elaborately signed the painting, a famous example of artistic self- 
inscription in European art, and indeed an exceptional practice in its period (cf Seidel 1993: 3). That signature develops a metonymic relationship with the vague figures on the mirror, and it constitutes a major assertion of authorial will and authorial presence - all the more so since, rather than just signing, Van Eyck inscribed the painting with the statement: "Johannes de Eyck fuit hic" [Jan Van Eyck was here].

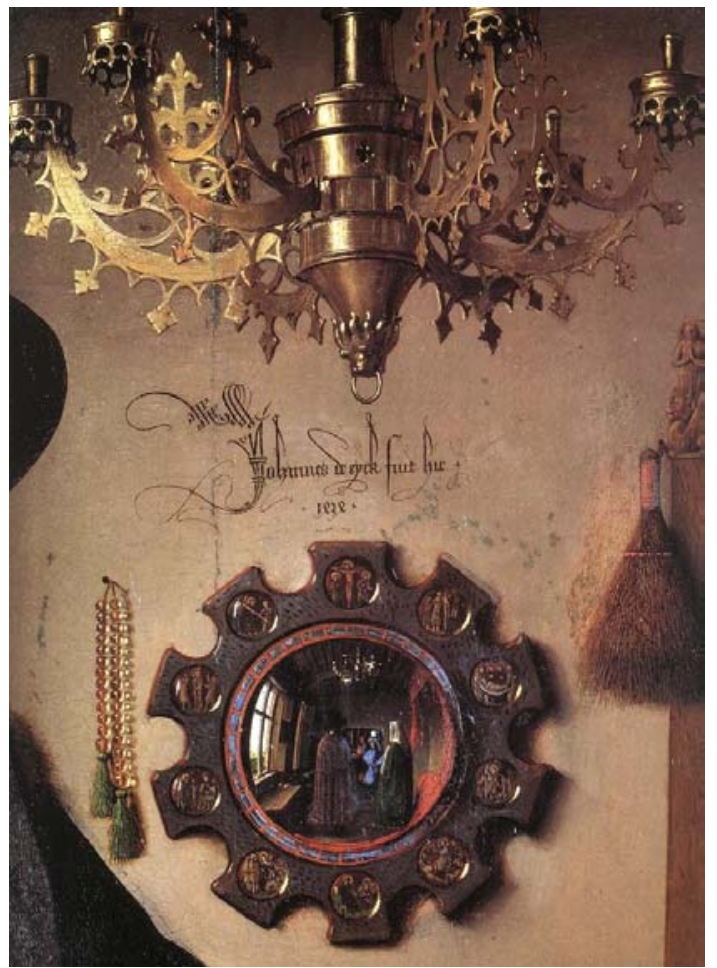

With such a celebrated precedent it can hardly be accidental that in Green's painting the mirror shows us the backs of the couple and no one else: the Joscelynes pose before a void, a conspicuous absence, somehow mirrored in the (obvious) non-pregnancy of the mature bride, as against what appears to be the exuberant pregnancy of Giovanni Arnolfini's wife. The fact that the left hand of both women is held in front of their bodies, Arnolfini's resting on (or caressing) her womb, Joscelyne's hanging limp, reinforces the quotation - but also the visual antithesis, an instance, indeed, of parody as "repetition with critical distance", in Linda Hutcheon's wellknown formula (Hutcheon 1985: 6, 37).

A representational dimension of this parodic design that seems to have attracted Muldoon's interest concerns ostentation, the way in which the couples portrayed signify through their surroundings - both lavish in their different ways. In Anthony Green's painting that lavishness, rather than identifying the power and wealth which discreetly transpires from the Arnolfini portrait, becomes the cluttered and hyperdecorated living room of a middle-class British home, its multipatterned furnishings and linings flashing in a riot of reds and yellows. This is in fact magnified by Green's naif (or rather, fauxnaï) style —which institutes a comfortable distance between his figurative art and anything that might resemble a "photographic" type of realism, a distance which is all the more important when representations of posing married couples have long found their commoner media in the snapshot or the home video; it is also buttressed by Green's refusal to abide by Renaissance perspective and (as he puts it in an interview given in 1996) by the "rectangular" arrangement of "this multiplicity of images within the memory", that "endless supply of information about your living room" (Wingfield 1996). In the middle of that visual exuberance stand $\mathrm{Mr}$ and Mrs Stanley Joscelyne; the opening of Muldoon's poem stresses precisely that overabundance of objects and detail, and, above all, its ruling sense of propriety and / as property. The latter term is indeed the resting point, the mot juste ultimately found by the alliterative, nearly stammer-like sequence of the also very long first line: "Standing as they do, all primped, primed, pukka, all proper, all property-lined, in a room / where every rift's loaded with ore" (Muldoon 2002: 32).

This setting, as painted by Green, seems to rest on a sense of balance, of meeting expectations - even if yielding to a penchant for kitsch; a contemporary realist and a practitioner of post-abstract art, Green described himself as "very self-conciously zeroing into that area which is the "everyman way of looking at the world'. I'm now very aware how the man in the street gets through his visual day. Because he uses his memory of things seen, of past experience, to actually get through" (Wingfield 1996). This is a view of art's relationship to the real which one might easily argue to be both congenial and alien to Muldoon's poetics. Muldoon has often made a point of writing about the ordinary and the everyday - to the point of publishing a collection, The Prince of the Quotidian (1994), whose rationale and justification was simply writing a poem per day in the course of a 
month, ingeniously foregrounding the randomness of programmed creation, whilst ostensibly refusing to sacralise the "inspirational" moment; but he has also rather often satirised the pieties of aurea mediocritas, of domestic bliss and family life ${ }^{2}$. It should not go unnoticed that the fourteen lines of "Anthony Green: The Second Marriage" identify it as one of the many experiments with the form of the sonnet which have long punctuated Muldoon's output —and that his choice of the longest-lived of lyrical forms, proposed as a single stanza which Muldoon writes as a single sentence, may indeed be read as an equivalent to the tidy living room of Green's piece. In fact, though, as soon as the opening description has been proffered, "Anthony Green: The Second Marriage" will promptly unbalance the neat (even if also ironical) symmetries of Green's painting, with its decorous scene of marriage and mat(ch)ing, by reading into it a narrative of transgression and imminent sentencing:

they're reminiscent less of a blushing bride and a nervous groom

than a pair of con artists summoned before a magistrate inclined to throw

the book at con artists

(Muldoon 2002: 32)

This narrative, which projects the otherwise decorous "Mr and Mrs Stanley Joscelyne" into disrepute, and substitutes contentiousness for composition, also provides a justification (other than the artistic pose) for the way in which the couple face the beholder. In other words, Muldoon's verbal rendering of Green's visual representation fills the empty space which the mirror at the back of Green's painting so blatantly exposes, and inscribes it with the presence of a judge, a figure of authority and definitive pronouncements - $\mathrm{a}$ magistrate whose job, in Muldoon's construction, is not to perform a wedding. And a homology is promptly defined: the ekphrastic gesture entails that, for the sake and within the space of his poem, the poet is indeed (to retrieve Muldoon's own critical dictum) "the first person to read" Green's painting and to pronounce on it -a pronouncement whose verbal substance and medium are weightily, magisterially conveyed by the phrase, "to throw / the book at ...". Indeed, through ekphrasis, "the book", as a metonym for texts, is thrown at other artists; and it may not be amiss to read in Muldoon's chosen phrasing for an authority which is verbally conveyed the suggestion that all the artists involved in the intermedial process are somehow "con artists": since that process is defined by appropriations, all who take part in it are conjoined under a suspicion of fraud, of the illicit appropriation and practice of another's craft, of playing with (inevitably) false appearances. Or yet of dealing in stolen goods - since that is the (jocular) drift taken by Muldoon's narrative of the Joscelyne court case, as the single sentence which forms the poem ironically proceeds to query the propriety and (indeed) property of that living room by shifting the condition of "receiver" from him who appropriates and verbally refigures the scene painted by Green onto the portrayed figures:

it looks very much as if, for Mr Stanley Joscelyne and his mate,

the case will turn

rather on the provenance of a single inanimate object - that silver cigarette urn,

it would appear, set on the occasional table

in the center of the room - and the outcome is, as he himself would put it, "inevitable".

(Muldoon 2002: 32)

Muldoon's postulation of a judge's authoritative gaze and discourse is indistinguishable from his own assumption of power over this scene. It is, after all, his creation, from the emplacement and empowerment of the "magistrate" down to the "inevitability" of a sentence whose determinateness is acknowledged through the inverted commas which signal the authorial ascription of discourse (apparently) to the "con artist" - even if non-disclosure of the sense and contents of "the outcome" somehow queries and qualifies the assertiveness of the final word. That postulation of a judicial, magisterial presence, however, is only made possible by the gaze of the Joscelyne couple, in (or from) the picture. Muldoon pretends not to recognise Green's (faux-) naïf style, its figurative simplicity —which somehow favours the narrative design (as against that sense of the captured single and "still" moment which more promptly arises from other forms of visual realism — cf Steiner 1988: passim). And that pretence on the part of the poet is an occurrence of what James A.W. 
Heffernan has termed "representational friction", a mismatch between "the dynamic pressure of verbal narrative" and "the fixed forms of visual representation" (Heffernan 1993: 19), in view of which some kind of redress is required. In other words, the static pose and the apparently earnest gaze of the Joscelyne couple have to be accounted for, they necessitate a source of awe, and this enables Muldoon's judicial narrative. Further, the object singled out by the judge's gaze and discourse refocuses the painting in a way which may be all too aware of the Van Eyck quotation: within the pictorial space of the Arnolfini portrait, the point which is equivalent to Green's “occasional table" and its "silver cigarette urn" is occupied by the mirror, with its proof of presence, and by the adjoining authorial signature. But Muldoon's lexical choice to designate the "single inanimate / object" that attracts and focuses the judicially construed gaze is not innocent either - an "urn", one of those objects whose "singl[ing] out for special attention" are historically associated with "the earliest examples of ekphrastic poetry" (Mitchell 1994: 165-6): the iconoclasm inherent in the verbal refiguration of the scene painted by Green is thus balanced by a gesture of acknowledgment (sardonic though it may be) of the longest of traditions in the verbal representation of visual art.

The above will have shown that Muldoon's ekphrastic practice foregrounds and queries some of the most persistent themes in the study of the relationships between literature and the visual arts -issues such as representation, authorship, and meaningwhich are also (and not by chance) fundamental topics in poststructuralist critical discourse. In this as in other cases, Muldoon seeks predominantly figurative painting for the object of such poems, but the fact that this preference entails the production of verbal representations of visual representations (to cite Heffernan's well-known formula; Heffernan 1993: passim) will hardly offer the reader the "reassurance" of literality, of a "transparent" rendering. In fact, Muldoon's ekphrastic poems blatantly become (thematically and otherwise) "like" his other work - those of his poems which do not ostensibly set out to represent a previous representation by another artist - and this should alert his readers to the refiguration which is starkly put in evidence by any visual confrontation with Muldoon's pictorial referents.

His practice certainly offers a confirmation of that "dynamic and obstetric" characteristic which Heffernan attributes to ekphrasis: "it typically delivers from the pregnant moment of visual art its embryonically narrative impulse, and thus makes explicit the story that visual art tells only by implication" (Heffernan 1993: 5). But the implications verbally elicited by Muldoon from that visual "story" tend to be of such a kind that, in the enactment of the dual process into which W.J.T.Mitchell analyses ekphrasis - "(1) the conversion of the visual representation into a verbal representation ...; (2) the reconversion of the verbal representation back into the visual object in the reception of the reader" (Mitchell 1994: 164) - the visual recomposition of the painting in the reader's consciousness will be, radically and in all respects, another representation. Projecting "Mr and Mrs Stanley Joscelyne" from their decorous middle-class life to the identity of "con artists", and construing their living room (the spatial witness to their married bliss) as a courtroom at the point of delivering a sentence, is only a distinctive example of a "reconversion" to be found repeated elsewhere amidst Muldoon's ekphrastic ventures - and indeed, with regard to that tension between inevitability and puzzlement at the close of the poem, a confirmation that "tales told within [his] poems become shaggy-dog stories" (Burt 2004: 15). After all, the authoritativeness of that refiguration, in itself as in the contents of a narrative whose outcome is pronounced "inevitable", runs directly counter to Muldoon's self-description as "antiprescriptive", as resisting "any kind of ism, that insists on everything falling into place very neatly" (interview cited by Burt 2004: 18).

The consequences of this in destabilising meaning, querying the ostensible determinacy of figurative visualisation, will be only too obvious. But some emphasis should also be laid on the implications of Muldoon's refigurations, under titles which explicitly name the painters, for an understanding of the authorial condition and of its adjoining sense of origin. As suggested above, Muldoon's explicit acknowledgment of authorship when 
his referents are visual artefacts is exceptional in the broader context of his intertextual practice -where silent appropriation more usually alternates with factually (and ironically) "wrong" attributions ${ }^{3}$. However, placing a poem in an ostensibly substitutive relationship with a painting (since it borrows the name of its author and its title), only to perform the kind of refiguration described above, is no more than the reverse of Muldoon's assumption of the texts of others under his own name; in both cases, the appropriated artefact is "refracted" (to borrow a term from translation studies - cf Lefevere 2000: passim) through Muldoon's poetry, so as to read (and "look") like one of his "original" creations. Finally, this complex combination of deference and subversion with regard to authorship finds a parallel ambivalence in the uncertain conformation that Muldoon proposes for the intermedial relation, making his poetry a space of undecidability also with regard to whether the visual is assumed by the verbal on a basis of contention or of composition, of agon or of "sisterly" mutuality. This is indeed a confirmation of the "Janus face" of ekphrasis: whilst "promising to give voice to the allegedly silent image", it yet attempts "to overcome the power of the image by transforming and inscribing it" (Wagner 1996: 13). In that respect, though, his work does no more than offer, albeit with the excitement afforded by some of the more daring practices highlighted above, further confirmation of the longest-lived argumentative nexus within discourse on intermediality.

\section{NOTES}

1. The controversy as to whether Van Eyck's painting indeed represents a marriage contract is in this case immaterial: the painting was repeatedly read as offering such a representation, and it is that traditional reading, rather than its questioning, that proves relevant to my argument.

2. A case in point being a poem like "The Wishbone", a dysphoric family reunion of just the poet and his father - "Maureen in England, Joseph in Guelph, / my mother in her grave" - for a Christmas TV dinner of "frozen chicken" (Muldoon 2001: 159).

3. One of the most daring instances of this consisting of two lines which conflate Gone with the Wind's Scarlett

O'Hara on Tara, and Christ on Gethsamane: "Tomorrow is another day, / As your man said on the Mount of Olives." (Muldoon 2001: 81).

\section{REFERENCES}

Burt, Stephen. 2004. “'Thirteen or Fourteen': Paul Muldoon's Poetics of Adolescence”. Kendall and McDonald (eds.), Paul Muldoon. 6-25.

Gregson, Ian. 1996. Contemporary Poetry and Postmodernism: Dialogue and Estrangement. Basingstoke: Macmillan.

Heffernan, James A.W. 1993. Museum of Words: the Poetics of Ekphrasis from Homer to Ashbery. Chicago, Ill.: Chicago U.P.

Homem, Rui Carvalho. 2004. "Of Beards and Breasts, Baldheads and Babies: Muldoon's Mongrel Families". Neil Sammells (ed.), Beyond Borders: IASIL Essays on Modern Irish Writing. Bath: Sulis Press. 178-90.

Hutcheon, Linda. 1985. A Theory of Parody: the Teachings of Twentieth-Century Art Forms. New York and London: Methuen.

Kendall, Tim. 1996. Paul Muldoon. Bridgend: Seren.

Kendall, Tim and Peter McDonald (eds.). 2004. Paul Muldoon: Critical Essays. Liverpool: Liverpool U.P.

Lefevere, André. 2000. "Mother Courage's Cucumbers: Text, system and refraction in a theory of literature" (1982), Lawrence Venuti (ed.), The Translation Studies Reader. London: Routledge. 233-49.

Louvel, Liliane. 2002. Texte / Image: Images à Lire, Textes à Voir. Rennes: Presses Universitaires de Rennes.

Lyon, John. 2004. “'All That': Muldoon and the Vanity of Interpretation”. Kendall and McDonald (eds.), Paul Muldoon. 110-24.

Mitchell, W.J.T. 1986. Iconology: Image, Text, Ideology. Chicago and London: Univ of Chicago Press.

Mitchell, W.J.T. 1994. Picture Theory: Essays on Verbal and Visual Representation. Chicago and London: Univ. of Chicago Press.

Muldoon, Paul. 1994. The Prince of the Quotidian. Loughcrew: Gallery. 1998. "Getting Round: Notes Towards an Ars Poetica". Essays in Criticism XLVIII:2 (April): 107-28 2000. To Ireland, I: The Clarendon Lectures in English Literature 1998. Oxford: O.U.P. 
2001. Poems 1968-1998. London: Faber.

2002. Moy Sand and Gravel. London: Faber.

Rice, Adrian and Angela REID (eds). 2002. A Conversation Piece: Poetry and Art. Newry: The National Museums and Galleries of Northern Ireland / Abbey Press.

Seidel, Linda. 1993. Jan Van Eyck's Arnolfini Portrait: Stories of an Icon. Cambridge: C.U.P.

Steiner, Wendy. 1988. Pictures of Romance: Form Against Context in Painting and Literature. Chicago and London: Univ. of Chicago Press.

Thomas, Julia (ed.). 2001. Reading Images. Houndmills: Palgrave.

Wagner, Peter (ed). 1996. Icons-Texts-Iconotexts: Essays on Ekphrasis and Intermediality. Berlin: Walter de Gruyter.

Wills, Clair. 1998. Reading Paul Muldoon. Newcastle: Bloodaxe.

Wingfield, Mark.1996. "Anthony Green, Painter, interviewed by Mark Wingfield on 19th. January 1996", http://www.cipherarts.com/green/grhtml/inter.html 